\title{
Rheumatoid arthritis treatment with TNF inhibitors and alternative procedures in case of its failure - results of the Polish survey in the context of EULAR recommendations
}

\author{
Małgorzata Tłustochowicz ${ }^{1}$, Grażyna Dębowska², Joanna Spytek ${ }^{2}$, Witold Tłustochowicz ${ }^{1}$ \\ ${ }^{1}$ Department of Internal Medicine and Rheumatology, Military Institute of Medicine, Warsaw, Poland \\ ${ }^{2}$ Roche Polska Sp. z o.o., Warsaw, Poland
}

\begin{abstract}
Introduction: According to the European League Against Rheumatism (EULAR), rheumatoid arthritis (RA) treatment aims to achieve remission or low disease activity (LDA) within 6 months. In Poland, despite the existence of the National Health Fund Drug Program (NHF-DP), data on the effects of treatment with biological agents in patients with RA are not publicly available. Also we cannot compare registers from other countries with the Polish results because the rules of the therapeutic program in Poland impose restrictions that do not exist in other countries. For this reason, the data will not be comparable, but the results of the currently used regimen for biological treatment in Poland should be analyzed and compared with the recommendations of the European EULAR as a contribution to further discussion.

Objectives: To determine the tumor necrosis factor $\alpha$ (TNF- $\alpha$ ) inhibitor treatment patterns in RA patients in Poland, to evaluate the frequency and causes of treatment failure as well as post-failure recommendations, and to compare Polish clinical practice enforced by the therapeutic program with the EULAR recommendations.

Material and methods: The data on 895 RA patients were retrospectively collected from routine medical records. A questionnaire was completed only once for each patient.

Results: After 3 months of treatment with a TNF- $\alpha$ inhibitor, the therapeutic target was achieved in $72 \%$ of patients: $4 \%$ in remission, $8 \%$ LDA, and $60 \%$ with moderate disease activity (MDA); after 9 months, $46 \%$ had reached the target: 16\% in remission, 30\% with LDA. An average of $49 \%$ of patients presented with MDA or high disease activity (HDA), thus requiring treatment modification. Treatment failure was confirmed in $14 \%$ of patients and a modified therapy administered: rituximab (72\%) or adalimumab (20\%). The most common cause of failure was inefficacy of treatment (70\%). Conclusions: In the Polish therapeutic program, despite the persistence of MDA or HDA, the treatment with TNF inhibitors rarely qualifies as ineffective and therefore is seldom modified by switching to another biologic drug. As long as the initiation of treatment and its modifications are enforced by the NHF-DP and not the recommendations of EULAR, treatment may be less effective and paradoxically cost-intensive. Therefore, it seems obvious that it is necessary to change and adapt the NHF-DP requirements to European standards.
\end{abstract}

Key words: rheumatoid arthritis, TNF inhibitors, treatment failure, treatment modification.

\footnotetext{
Address for correspondence

Małgorzata Tłustochowicz, Department of Internal Medicine and Rheumatology, Military Institute of Medicine, Szaserów 128, 04-141 Warsaw, tel. +48 501757 774; fax +48 2268169 20, e-mail: m.tlustochowicz@gmail.com

Submitted: 17.12.2015; Accepted: 20.08.2015
} 


\section{Introduction}

Biological drugs used in rheumatoid arthritis (RA) increase the chance of achieving both clinical remission and low disease activity (LDA), as well as giving individual patients physical independence. The most important predictor of remission and LDA after 1 year of treatment is treatment efficacy in the first 3 months [1]. The individual response to tumor necrosis factor (TNF) inhibitor treatment varies, but generally one-third of RA patients responded to treatment very well, another one-third responded well, and in the remaining patients treatment did not improve patients' health status [2]. In available registries of biological treatment, the percentage of patients for whom treatment failure with a TNF inhibitor was reported ranges from 21\% (DANBIO registry) to 38\% (LOHREN registry) [3]. According to the 'treat to target' concept promoted by the European League Against Rheumatism (EULAR) [4] and developed further in therapeutic recommendations [5], the objective of each therapy, including using biological drugs, is to achieve remission or at least LDA after 6 months of treatment. It should also be noted that in accordance with the 2013 EULAR recommendations, after 3 months of treatment, at least moderate disease activity (MDA) should be achieved in patients who began their RA treatment in a stage of high activity. In all other cases, treatment failure is defined as requiring modification of the current procedure by adjusting the dose of a disease-modifying anti-rheumatic drug (DMARD) or replacement of one biological drug for another.

In Poland, the biological treatment of RA was carried out within the framework of the National Health Fund Drug Program (NHF-DP), until the end of 2012. During this period in the treatment of RA in Poland the following biological drugs were available: TNF inhibitors (infliximab, etanercept, adalimumab) and rituximab (a chimeric anti-CD20 monoclonal antibody) [6]. According to the NHF-DP, TNF inhibitors have been used in the first-line therapy in all patients. In the case of failure, rituximab was administered. In Poland, no data have been published on the effectiveness of TNF inhibitor treatment regulated by a program, and the data from the register of biological treatment of RA conducted by the National Health Fund are also not available.

The objective of this study was to determine TNF inhibitor treatment patterns in RA patients in Poland, to evaluate the frequency and causes of treatment failure as well as post-failure recommendations. Also the aim of the study was to draw attention to the need to compare and to adapt the current NHF program to the standards set out by EULAR.

\section{Material and methods}

The study involved 36 centers, which treated RA patients with biological drugs under the NHF-DP and agreed to participate. One of the NHF-DP eligibility criteria is an aggressive course of RA and high activity of the disease, defined as a Disease Activity Score 28 (DAS28) above 5.1. Data were collected retrospectively from available medical records, using an electronic questionnaire. The study covered all patients treated with TNF inhibitors, who between January and June 2012 had a follow-up visit after 3 or any subsequent 6 months of treatment. For each patient, the questionnaire was completed only once. The following data were collected during the follow-up: age, sex, duration of RA, previously and currently used TNF inhibitors (including monotherapy in combination with methotrexate), treatment duration, DAS28-OB, calculated using the EULAR recommendations, C-reactive protein (CRP) concentration and ESR (erythrocyte sedimentation rate) [7, 8]. Additionally, in the case of treatment failure, as defined by the NHF-DP, data on the cause and type of recommended procedure were collected.

Statistical analyses were performed using SPSS software, version 10. Duration of disease, duration of previous and current TNF- $\alpha$ inhibitor treatment, CRP concentration, ESR level, and DAS28 indicators were presented as means \pm standard deviation (SD), with minimum and maximum. For independent comparison, Student's $t$ test was used, and for non-normally distributed variables the Mann-Whitney $U$ test was used. One-way ANOVA was used to test significant differences in the average time of drug admission and the average values of CRP, $\mathrm{OB}$ and DAS28 in patients treated with different drugs. The $p$-value $<0.05$ was considered statistically significant.

\section{Results}

Data were collected on 895 [736 women (82\%)] patients with RA treated with TNF inhibitors (65.5\% of all patients treated with TNF inhibitors at this time). Average disease duration was $10.6 \pm 7.5$ years (range: $1.16-32.52$ years); $46 \%$ of patients had suffered from RA for more than 10 years. Patients were treated with etanercept ( $n=564 ; 63 \%)$, adalimumab ( $n=278 ; 31 \%)$, and infliximab ( $n=53 ; 6 \%)$. In 771 patients (86\%), a TNF inhibitor had been used as first-line therapy, and in 14\% of patients ( $n=124$ ) as second-line biological therapy; in the latter group, $82 \%$ used adalimumab, which resulted from the previous NHF-DP recommendations. In 694 (78\%), a TNF inhibitor was used in combination with methotrexate (in different doses - 7.5-25 mg/week), and in 199 (22\%) as monotherapy. 
Duration of biological drug administration was 18.5 \pm 13.3 months (2.6-127.6 months). The number of patients treated with a TNF inhibitor in 6-month intervals is shown in Fig. 1. The majority of patients $(n=760)$ took the medication for up to 2.5 years (Fig. 1$)$.

Nearly half of the patients ( $n=439 ; 49 \%)$ suffered from MDA or high disease activity (HDA) (Fig. 2).

Of 179 patients for whom data were collected after 3 months of treatment (the first follow-up visit), remission was reported in 7 (4\%), LDA in 14 (8\%), MDA in 108 (60\%), and HDA in 50 (28\%) (Table I). During the second follow-up, which according to the NHF-DP was after 9 months of treatment, data were collected for 161 patients. Twenty-six of these (16\%) were in remission,

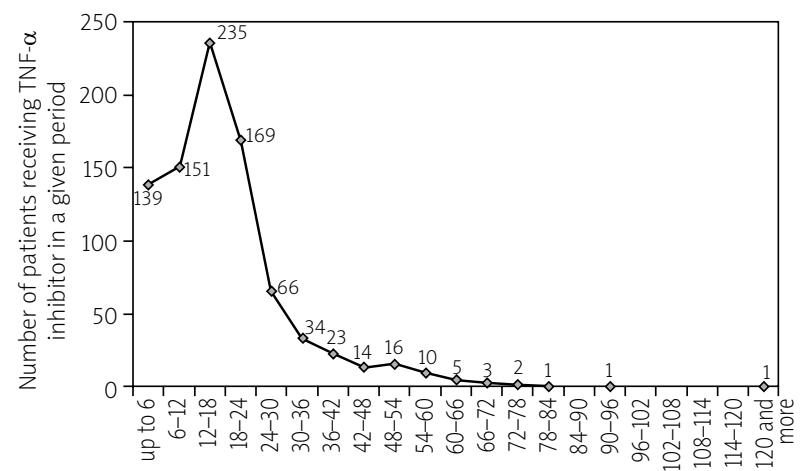

Fig. 1. Duration of currently used TNF inhibitors (6-month intervals).
49 (30\%) had LDA, and 86 (54\%) presented as having no therapeutic effect, as they had MDA or HDA (Table I). Different, but high, numbers of patients evaluated during the third and subsequent follow-up visits had MDA and HDA (26-63\%) (Table I).

Mean DAS28 values for patients receiving different TNF inhibitors in a given time period are shown in Fig. 3.

During the follow-up, the average CRP level was 9.49 $\mathrm{mg} / \mathrm{l}$, and ESR $22.36 \mathrm{~mm} / \mathrm{h}$. Differences between average levels of CRP and ESR for patients receiving various TNF inhibitors were not significant statistically.

During the follow-up, treatment failure according to NHF-DP definitions was confirmed in 128 (14\%) patients, in whom treatment modification was implemented.

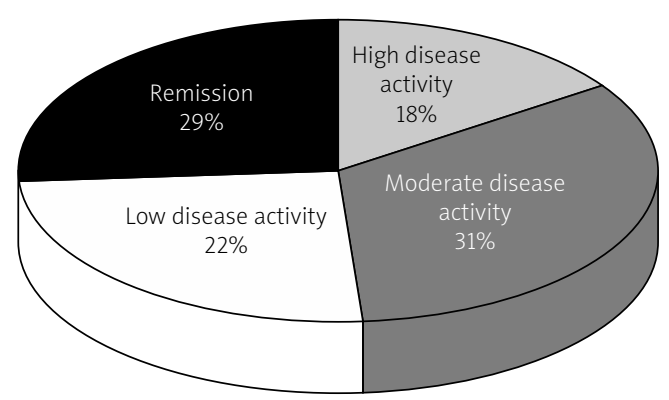

Fig. 2. Distribution of DAS28-OB $(n=895)$.

Table I. Profile of disease activity according to the DAS28-OB during the follow-up. Data shown as number of patients $(n)$ and proportion (\%)

\begin{tabular}{|c|c|c|c|c|c|c|c|c|c|}
\hline \multirow{3}{*}{$\begin{array}{l}\text { Follow-up visits } \\
\text { (according to } \\
\text { the time of drug } \\
\text { administration) }\end{array}$} & \multicolumn{9}{|c|}{ Disease activity according to the DAS28 } \\
\hline & \multicolumn{2}{|c|}{ Remission } & \multicolumn{2}{|c|}{ Low activity of RA } & \multicolumn{2}{|c|}{$\begin{array}{c}\text { Moderate activity } \\
\text { of RA }\end{array}$} & \multicolumn{2}{|c|}{ High activity of RA } & \multirow{2}{*}{$\begin{array}{c}\text { Tota } \\
n\end{array}$} \\
\hline & $n$ & $\%$ & $n$ & $\%$ & $n$ & $\%$ & $n$ & $\%$ & \\
\hline Visit 1 (3 months) & 7 & 4 & 14 & 8 & 108 & 60 & 50 & 28 & 179 \\
\hline Visit 2 (9 months) & 26 & 16 & 49 & 30 & 62 & 39 & 24 & 15 & 161 \\
\hline Visit 3 (15 months) & 106 & 43 & 76 & 31 & 44 & 18 & 20 & 8 & 246 \\
\hline Visit 4 (21 months) & 72 & 51 & 26 & 18 & 23 & 16 & 20 & 14 & 141 \\
\hline Visit 5 (27 months) & 18 & 33 & 16 & 30 & 11 & 20 & 9 & 17 & 54 \\
\hline Visit 6 (33 months) & 7 & 29 & 3 & 13 & 10 & 42 & 4 & 17 & 24 \\
\hline Visit 7 (39 months) & 4 & 20 & 6 & 30 & 5 & 25 & 5 & 25 & 20 \\
\hline Visit 8 (45 months) & 7 & 54 & 1 & 8 & 2 & 15 & 3 & 23 & 13 \\
\hline Visit 9 (51 months) & 1 & 6 & 5 & 31 & 6 & 38 & 4 & 25 & 16 \\
\hline Visit 10 (57 months) & 2 & 40 & 1 & 20 & & 0 & 2 & 40 & 5 \\
\hline Visit 11 (63 months) & 4 & 67 & 2 & 33 & & 0 & & 0 & 6 \\
\hline $\begin{array}{l}\text { Visit } 12 \text { and later } \\
\text { ( } \leq 69 \text { months) }\end{array}$ & 1 & 3 & 2 & 7 & 7 & 23 & 20 & 67 & 30 \\
\hline
\end{tabular}




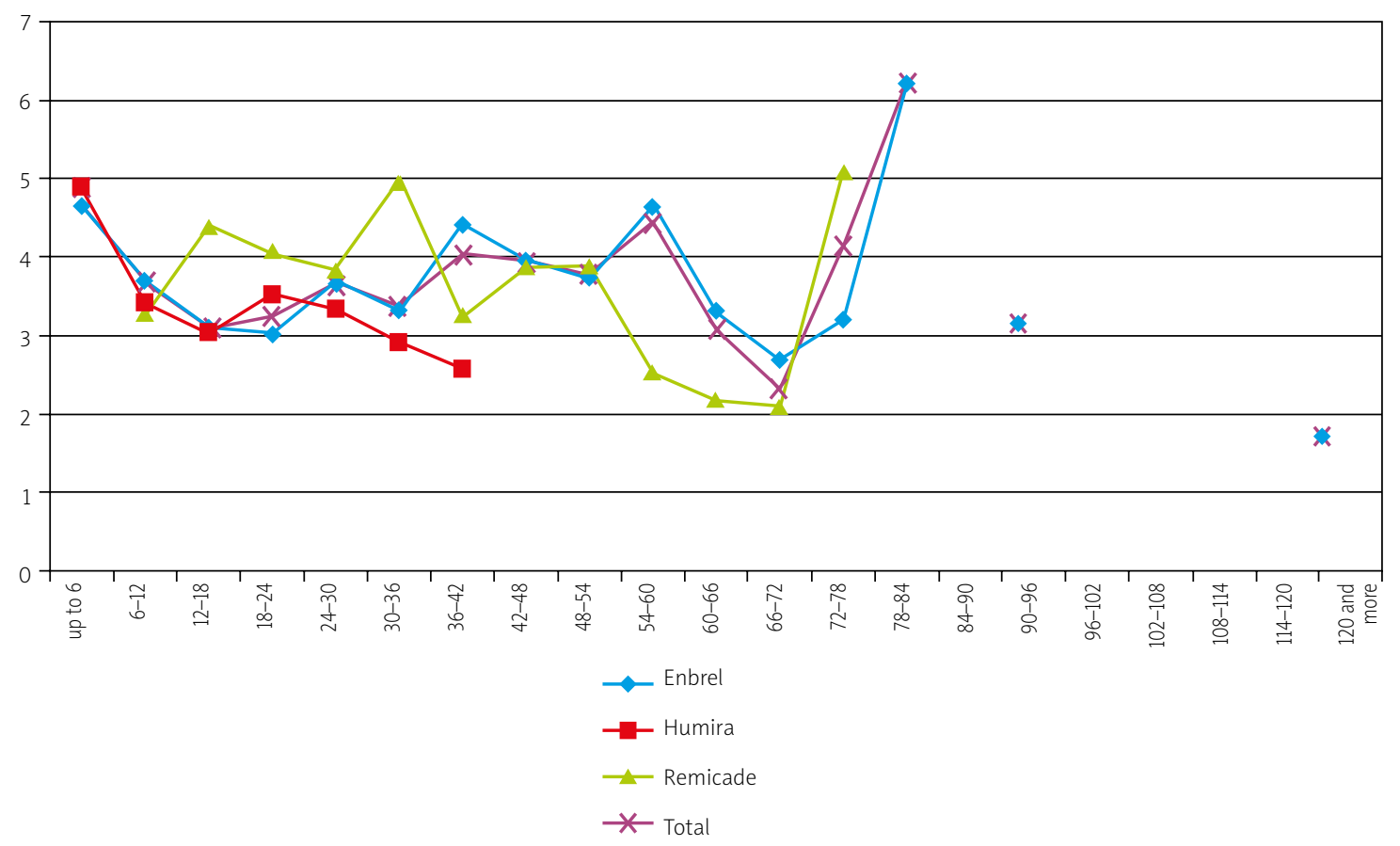

Fig. 3. Duration of treatment with TNF inhibitors by drug and DAS28.

Almost $25 \%$ of these patients were previously treated with another TNF inhibitor: etanercept (58\%), infliximab (36\%), and adalimumab (6\%). The reason for treatment failure of TNF inhibitors are presented in Fig. 4. The most frequent reasons for treatment failure were loss of efficacy $(n=90 ; 70 \%)$ or initial lack of efficacy $(n=26$; $20 \%)$; adverse events (AEs) $(n=12 ; 9 \%)$ and other causes $(n=5 ; 4 \%)$ were less frequent. The duration of treatment with a TNF inhibitor did not differ between patients in whom treatment failure was observed and those who continued treatment; in both groups, the reported mean duration of treatment was 1.5 years. In contrast, patients with treatment failure were characterized by higher DAS28, CRP concentration, and ESR level $(p<0.001)$. The treatment with TNF inhibitor was interrupted in 110 patients. Another biological treatment was administered in 98 (77\%), most commonly with rituximab $(n=70 ; 71 \%)$ or another TNF inhibitor $(n=28$; $29 \%$ ). In $13 \%$, the glucocorticoid dose was increased, and DMARDs were modified in $8 \%$ of patients; sometimes more than one measure was used (Fig. 5).

\section{Discussion}

Joint damage, physical disability and reduction in quality of life $(\mathrm{Q} O \mathrm{~L})$ are the main complications of the inflammatory process in RA. Premature mortality is also observed in patients with RA. A good predictive factor of

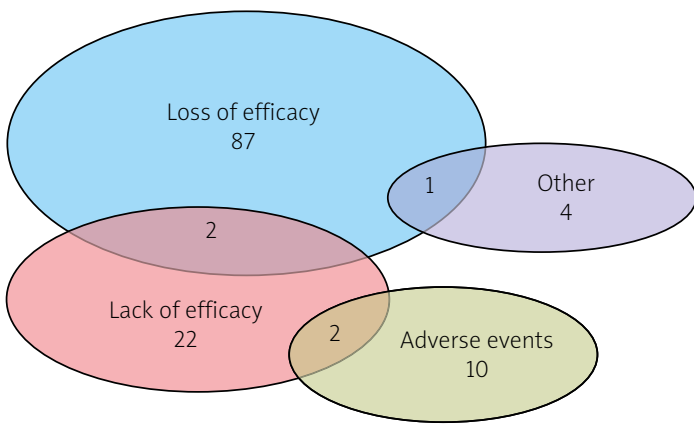

Fig. 4. Reasons for treatment failure with TNF inhibitor

the above is the disease activity expressed by the number of swollen joints, as well as reactive indicators or complex indicators of disease activity such as DAS28. In many patients, in daily practice, remission is an achievable goal, and its rapid achievement can stop joint damage, regardless of the type of treatment - by synthetic or biological drugs. Low activity of the disease (LDA), particularly in a stable form that lasts for many years, may be an alternative goal. In our study population, the average duration of RA was 10.6 years and, therefore, as a measure of treatment effectiveness, achieving LDA was also considered. The Polish therapeutic program defines remission as DAS28 $<2.6$, and LDA as DAS28 be- 
$D M A R D$ - disease-modifying anti-rheumatic drug

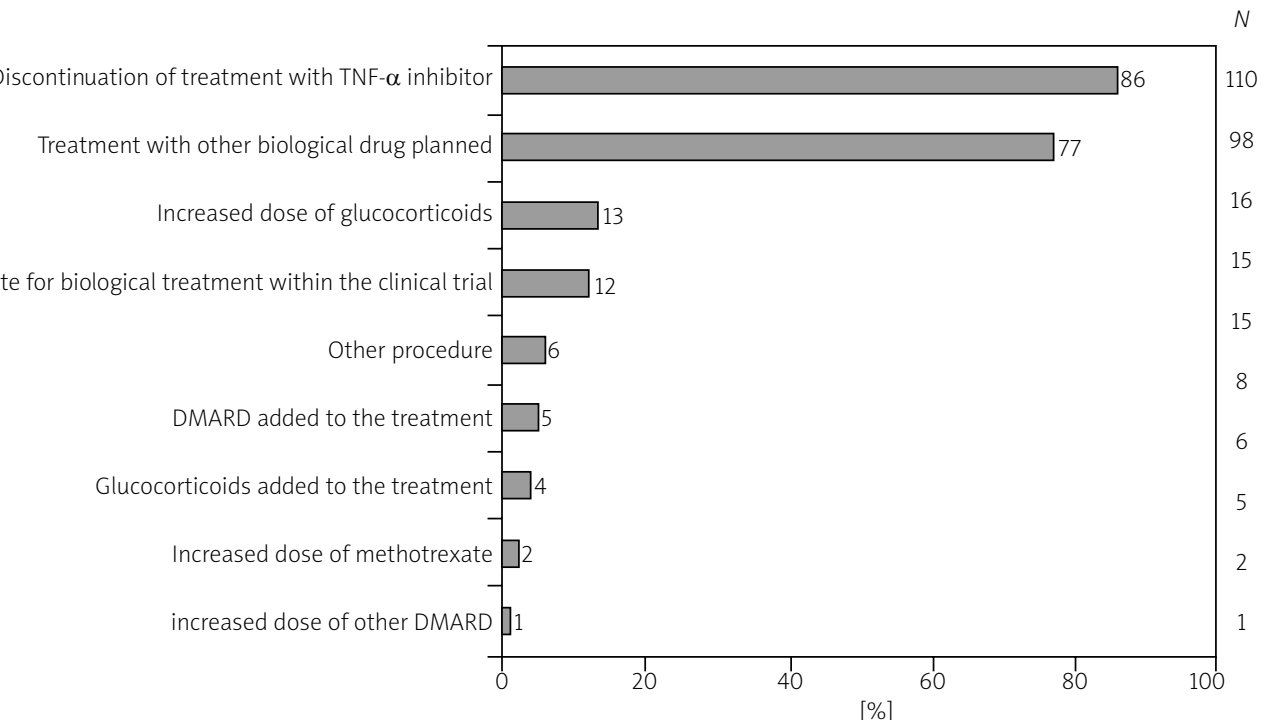

Fig. 5. Treatment modifications after confirmed treatment failure (multiple choices allowed).

tween 2.6 and 3.2. Only patients with HDA (DAS28 > 5.1) are enrolled in the therapeutic program. Starting treatment with biological agents only when patients reach such high disease activity may be one of the reasons for lower efficacy of therapy in this group.

In the EULAR recommendations, if a patient does not achieve an improvement in health status after 3 months, such as a reduction from HDA to MDA, and after 6 months at least LDA, treatment should be modified by changing the medication to another biologic drug. On the other hand, the recommendations assume the continued use of biological drugs despite the achievement of LDA or remission, taking into account dose reduction or increasing the intervals between doses.

In the Polish NHF program a reduction in DAS28 of 1.2, which does not exclude the persistence of HDA (DAS28 $>5.1$ ), is important. According to EULAR recommendations the patient, at any stage of treatment, cannot have HAD [4]. Thus, the goal of treatment should be achieved within a maximum of 6 months [5]. In patients treated with TNF- $\alpha$ inhibitors in the Polish therapeutic program, the target in the third month of treatment, according to EULAR, was achieved by more than $70 \%$ of patients, and after 9 months, when LDA or remission is considered as a therapeutic effect, this rate was estimated at $46 \%$. In the Polish therapeutic program, the second follow-up is at the ninth month of treatment; thus, how many patients achieved the therapeutic target after 6 months of treatment cannot be assessed. Of note, more than half of the patients evaluated at the ninth month had MDA or HDA. According to EULAR recommendations, in the case of treatment failure, treatment should be modified after 6 months [5]. In our study, although treatment failure was formally, according to NHF definition, confirmed in only $14 \%$ of patients, the proportion of patients with MDA and HDA during the follow-up indicates that treatment failure with a TNF- $\alpha$ inhibitor occurred much more frequently.

Based on the published registry data, treatment failure using TNF inhibitors is estimated at 21.4-38.1\% [3]. The most common causes of treatment failure are inefficacy of treatment (16.9-46.4\%) and AE (18.2-30.6\%) $[3,9,10]$. Our results confirmed inefficacy as the most common cause of failure; AEs were less frequently reported. The higher level of AE reporting in countries with routine biological treatment registries [1] may explain this difference. Rituximab was used more often than any other TNF- $\alpha$ inhibitor as post-failure treatment modification. EULAR recommends another TNF inhibitor or other biological drug with a different mechanism of action (abatacept, rituximab or tocilizumab), after confirmation of TNF- $\alpha$ inhibitor treatment failure $[5,11]$. One TNF inhibitor is replaced by another in approximately $38 \%$ of patients [12]; in our study, nearly $25 \%$ of patients were given another TNF- $\alpha$ inhibitor in the past. No clinical trial data on the effectiveness of such changes are available, and recommendations are based solely on observational studies [5, 13-15]. No conclusions in this regard can be drawn from the GO-AFTER study with golimumab [16]. In this study, LDA was achieved in $12 \%$ of patients in the twenty-fourth week after replacing one TNF- $\alpha$ inhibitor with another; however, the majority of patients had previously been effectively treated with a TNF- $\alpha$ inhibitor, and that treatment was interrupted 
not because of treatment failure but because of side effects or other administrative reasons $[15,16]$. Administration of rituximab after the initial failure of a TNF inhibitor could be more beneficial than changing one TNF inhibitor for another [17-19]. It has been shown that patients in whom treatment failure using a TNF inhibitor was observed responded better (in terms of DAS28) when rituximab was introduced compared with other TNF inhibitors [20]. The efficacy of rituximab in such cases was the highest in seropositive patients (RF present or anti-CCP antibodies) and among those who had not previously received more than one biological drug [21, 22]. Another treatment modification reported after confirmed treatment failure was an increase in the dose of glucocorticoids. It should be noted, however, that such a procedure does not always improve treatment effects and often leads to treatment failure, with a considerable increase in the incidence of AEs; therefore, it should not be recommended [5, 23]. In contrast, dose adjustments of DMARDs, particularly methotrexate, were rarely reported, although as shown by other studies, in Poland it was often used in non-therapeutic doses, as shown by research in previous years, although now significant improvement is observed [24, 25]. In the context of the presented results, it appears that introducing biological drugs into rheumatological practice in Poland has not considerably changed the patient's situation, as described by Sokka et al. in 2007 [26]. It is necessary to underline the fact that in Poland there are much fewer biologically treated patients than in other countries according to e.g. the Quest-RA study, and the treatment starts at a very high activity of the disease [26]. Such a classification of patients may have an impact on the effectiveness of treatment. There is no doubt that the originally created and subsequently insufficiently modified NHF program standards of RA treatment with biological agents in Poland did not reflect, and still do not reflect, the EULAR recommendations.

\section{Conclusions}

The results of the study in Poland indicate that TNF- $\alpha$ inhibitor treatment failure defined by the therapeutic program has been confirmed less frequently in comparison with data from global registries of biological treatment. Based on the distribution of patients with MDA and HAD in Polish/our data, it should be considered that treatment failure occurs in a larger number of patients than actually reported. This situation is enforced by the rules of the therapeutic program, the fear of withdrawal of treatment with the patient and reduced decisions of doctors, who should also decide whether to continue or change therapy.
The data presented here relate to the period from 2012. Despite attempts to change the program, there are still significant differences between the international/EULAR recommendations and permitted (paid by the payer) treatment available.

\section{Acknowledgements}

The authors thank Roche Polska Sp. z o.o., Warsaw, Poland, for sponsoring this project and Proper Medical Writing, Warsaw, Poland for their assistance in the preparation of this paper.

\section{Conflict of interest:}

Grażyna Dębowska and Joanna Spytek are permanent employees of Roche Polska Sp. z o.o.

Witold Ttustochowicz - National Consultant in Rheumatology, Chief of Department of Internal Medicine and Rheumatology, Military Institute of Medicine, Warsaw, Poland, cooperates with Roche Polska Sp. z o.o. on the basis of fee-for-service contracts, e.g. delivering the lectures during Roche sponsored events.

\section{References}

1. Listing J, Strangfeld A, Rau R, et al. Clinical and functional remission: even though biologics are superior to conventional DMARDs overall success rates remain low-results from RABBIT, the German biologics register. Arthritis Res Ther 2006; 8: R66.

2. Wick MC, Ernestam S, Lindblad S, et al. Adalimumab (Humira) restores clinical response in patients with secondary loss of efficacy from infliximab (Remicade) or etanercept (Enbrel): results from the STURE registry at Karolinska University Hospital. Scand J Rheumatol 2005; 34: 353-358.

3. Hjardem E, Østergaard M, Pødenphant J, et al. Do rheumatoid arthritis patients in clinical practice benefit from switching from infliximab to a second tumor necrosis factor alpha inhibitor? Ann Rheum Dis 2007; 66: 1184-1189.

4. Smolen JS, Aletaha D, Bijlsma JWJ, et al. Treating rheumatoid arthritis to target: recommendations of an international task force. Ann Rheum Dis 2010; 69: 631-637.

5. Smolen J, Landewé R, Breedveld F, et al. EULAR recommendations for the management of rheumatoid arthritis with synthetic and biological disease-modifying antirheumatic drugs: 2013 update. Ann Rheum Dis 2014; 73: 492-509.

6. National Health Fund Drug Program 2012. Treatment of rheumatoid arthritis (RA) and juvenile idiopathic arthritis (IIA) with aggressive course [in Polish]. Annex 16 to Regulation No. 59/2011/DGL Chairman of the National Health Fund, 10 October 2011. Available at: http://www.nfz-lodz.pl/attachments/3379_Leczenie\%20RZS\%20i\%20MIZS\%200\%20przebiegu\%20agresywnym.pdf.

7. Van Cestel A, Prevoo M, van't Hof M, et al. Development and validation of the European League Against Rheumatism re- 
sponse criteria for rheumatoid arthritis. Arthritis Rheum 1996; 39: 34-40.

8. Prevoo ML, van't Hof MA, Kuper HH, et al. Modified disease activity scores that include twenty-eight-joint counts. Development and validation in a prospective longitudinal study of patients with rheumatoid arthritis. Arthritis Rheum 1995; 38: 44-48.

9. Hetland ML. DANBIO-powerful research database and electronic patient record. Rheumatology (Oxford) 2011; 50: 69-77.

10. Marchesoni A, Zaccara E, Gorla R, et al. TNF-alpha antagonist survival rate in a cohort of rheumatoid arthritis patients observed under conditions of standard clinical practice. Ann N Y Acad Sci 2009; 1173: 837-846.

11. Singh JA, Furst DE, Bharat A, et al. 2012 update of the 2008 American College of Rheumatology recommendations for the use of disease-modifying antirheumatic drugs and biologic agents in the treatment of rheumatoid arthritis. Arthritis Care Res (Hoboken) 2012; 64: 625-639.

12.van Vollenhoven R, Harju A, Brannemark S, et al. Treatment with infliximab (Remicade) when etanercept (Enbrel) has failed or vice versa: data from the STURE registry showing that switching tumour necrosis factor alpha blockers can make sense. Ann Rheum Dis 2003; 62: 1195-1198.

13. Hyrich KL, Lunt M, Dixon WG, et al. Effects of switching between anti-TNF therapies on HAQ response in patients who do not respond to their first anti-TNF drug. Rheumatology (Oxford) 2008; 47: 1000-1005.

14. Hyrich KL, Lunt $M$, Watson KD, et al. Outcomes after switching from one anti-tumor necrosis factor alpha agent to a second anti-tumor necrosis factor alpha agent in patients with rheumatoid arthritis: results from a large UK national cohort study. Arthritis Rheum 2007; 56: 13-20.

15. Greenberg JD, Reed G, Decktor D, et al. A comparative effectiveness study of adalimumab, etanercept and infliximab in biologically naive and switched rheumatoid arthritis patients: results from the US CORRONA registry. Ann Rheum Dis 2012; 71: 1134-1142.

16. Smolen J, Kay J, Daoyle MK, et al. Golimumab in patients with active rheumatoid arthritis after treatment with tumour necrosis factor alpha inhibitors (GO-AFTER study): a multicentre, randomised, double-blind, placebo-controlled, phase III trial. Lancet 2009; 374: 210-221.

17. Chatzidionysiou K, Lie E, Nasonov E, et al. Highest clinical effectiveness of rituximab in autoantibody-positive patients with rheumatoid arthritis and in those for whom no more than one previous TNF antagonist has failed: pooled data from 10 European registries. Ann Rheum Dis 2011; 70: 1575-1580.

18. Soliman MM, Hyrich KL, Lunt M, et al. Rituximab or a second anti-tumor necrosis factor therapy for rheumatoid arthritis patients who have failed their first anti-tumor necrosis factor therapy? Comparative analysis from the British Society for Rheumatology Biologics Register. Arthritis Care Res (Hoboken) 2012; 64: 1108-1115.

19. Soliman MM, Hyrich KL, Lunt M, et al. Effectiveness of rituximab in patients with rheumatoid arthritis: observational study from the British Society for Rheumatology Biologics Register. J Rheumatol 2012; 39: 240-246.
20. Finckh A, Ciurea A, Brulhart L, et al. B cell depletion may be more effective than switching to an alternative anti-tumor necrosis factor agent in rheumatoid arthritis patients with inadequate response to anti-tumor necrosis factor agents. Arthritis Rheum 2007; 56: 1417-1423.

21. Strangfeld A, Eveslage M, Listing J, et al. Effectiveness of treatment with rituximab depends on autoantibody status - results from 2 years of experience in the German biologics register RABBIT [abstract]. Arthritis Rheum 2009; 60 Suppl 10: 1695.

22. van Vollenhoven RF, Chatzidionysiou K, Nasonov E, et al. SixMonth Results From the Collaborative European REgistries for Rituximab in Rheumatoid Arthritis (CERERRA). Efficacy of Rituximab Is Highest in RF-Positive Patients and in Those Who Failed at Most One Prior Anti-TNF [abstract]. Arthritis Rheum 2009; 60 Suppl 10: 1671.

23. Bijlsma JW. Optimal treatment of rheumatoid arthritis: EULAR recommendations for clinical practice. Pol Arch Med Wewn 2010; 120: 347-353.

24. Tłustochowicz W, Filipowicz-Sosnowska A, Kucharz EJ, et al. Treatment of patient with rheumatoid arthritis in daily practice of rheumatologist - results of the nationwide survey [in Polish]. Reumatologia 2008; 46: 330-339.

25. Kulig M, Malec Z, Tłustochowicz W. Analysis of ambulatory treatment with methotrexate in patients treated for rheumatoid arthritis [in Polish]. Reumatologia 2009; 47: 202-206.

26. Sokka T, Kautiainen H, Toloza S, et al. QUEST-RA: quantitative clinical assessment of patients with rheumatoid arthritis seen in standard rheumatology care in 15 countries. Ann Rheum Dis 2007; 66; 1491-1496. 